\title{
'The object of sense and experiment': the ontology of sensation in William Hunter's investigation of the human gravid uterus
}

\author{
Richard T. Bellis* \\ School of Medicine, University of St Andrews, and Department of History, Durham University \\ *Corresponding author: Richard T. Bellis, Email: rtb8@st-andrews.ac.uk
}

\begin{abstract}
William Hunter's anatomical inquiry employed all of his senses, but how did his personal experiences with the cadaver become generalized scientific knowledge teachable to students and understandable by fellow practitioners? Moving beyond a historiographical focus on Hunter's images and extending Lorraine Daston's (2008) concept of an 'ontology of scientific observation' to include nonvisual senses, I argue that Hunter's work aimed to create a stabilized object of the cadaver that he and his students could perceive in common. Crucial to this stabilization was the sense of touch and its interaction with other senses, creating intersensory knowledge of the cadaver. Through a close reading of his neglected posthumous publication An Anatomical Description of the Human Gravid Uterus (1794), I demonstrate that Hunter wrote extensively about touch and other sensory experiences, using comparative metaphors and other linguistic strategies to engender clear ideas of the cadaver in the mind of the reader. That these ideas could be consistent between practitioners was guaranteed by God, but required practitioners to appropriately reflect on their sensory experiences with cadavers. Hunter's experimental practice encompassed both simple and complex methods, all aimed at increasing the range of sensorial experiences he had with the gravid uterus. His preservations of these experiences in text, image and preparation could then be used to support further anatomical investigations.
\end{abstract}

[T]o hold a correspondence with all the material beings which surround [us] ... organs [are] fitted to receive the different kinds of impressions, that they [materials] will make ... the organs of sense, as we call them: the eye is adapted to light; the ear, to sound; the nose to smell; the mouth, to taste; and the skin to touch. ${ }^{1}$

To his students, William Hunter stressed that they must acquire of anatomy 'distinct and clear ideas, especially of the objects of our senses', to become successful anatomists. ${ }^{2}$ Historians have stressed the visual aspects of Hunter's pedagogy: to see was to know, and so Hunter's students were trained to see appropriately through what Carin Berkowitz has characterized as 'systems of display' based on Lockean principles. ${ }^{3}$ In this

1 William Hunter, Two Introductory Lectures, London: J. Johnson, 1784, p. 74.

2 Hunter, op. cit. (1), p. 103.

3 Ludmilla Jordanova, 'Gender, generation and science: William Hunter's obstetrical atlas', in W.F. Bynum and Roy Porter (eds.), William Hunter and the Eighteenth-Century Medical World, Cambridge: Cambridge University Press,

(c) The Author(s), 2022. Published by Cambridge University Press on behalf of British Society for the History of Science. This is an Open Access article, distributed under the terms of the Creative Commons Attribution licence (https://creativecommons.org/ licenses/by/4.0/), which permits unrestricted re-use, distribution, and reproduction in any medium, provided the original work is properly cited. 
article, I stress that alongside and interacting with these systems of display were a range of other educational methods that worked to train students' observational skills with the senses, enabling them to investigate cadavers as objects or material in a Lockean framework (outlined in the epigraph to this article) and to experience that investigation in a normative manner. That is, not only were students trained to visually scrutinize the human body in preparation for dissection, but they were also trained to experience it through their own senses in a manner that was consistent with Hunter's own sensory experience of the cadaver. The result was that students' observations of the cadaver would be the same as Hunter's - they would perceive it in common. How this consistency of perception was engendered through Hunter's work is the focus of this article, following Lorraine Daston's call to investigate the ontology of scientific observation: 'how expert observation discerns and stabilizes scientific objects for a community of researchers'. ${ }^{4}$ In making a stabilized 'object' of the cadaver that trained students could discern, Hunter's sense of touch and the preservation of this sensation were of particular importance. As well as being important for anatomical knowledge in its own right, touch interacted with visual learning to give students intersensory ideas about the cadaver, such as its proportions and the textures of different tissues..$^{5}$ Moreover, preservations of touch also leave different material legacies compared to visual sources. This enables an expanded scope of analysis for Hunter's work that moves away from the focus on his famous illustrations, and links to the use of touch in other experimental disciplines in the eighteenth century, particularly that of chemistry. Touch is thereby the main sensory framework for my analysis.

Historians of science have increasingly questioned the idea that disciplining subjective experience out of observation was central to the development of the experimental philosophy in the seventeenth century. ${ }^{6}$ In fact, many 'subjectivities' were incorporated into scientific practices and representation. ${ }^{7}$ This was true in the eighteenth century too: Lissa Roberts has shown that eighteenth-century 'sensuous chemists' made 'chemical determinations by sensibly examining qualitative characteristics', which required chemists' bodies to be trained in discerning qualitative differences of substances in various states. ${ }^{8}$ That training was required to use the senses for scientific observation is an important point: not all sensory experience was appropriate. Daston describes the learning process of ontological observation as 'step by step, seminar by seminar, as apprentices learn to see like the masters', to the point where they gain 'tutored eyes' that converge with their master so that they 'see the same things'. 9 For Hunter, not only seeing but feeling, hearing,

1985, pp. 385-412, 393-4; Carin Berkowitz, 'Systems of display: the making of anatomical knowledge in Enlightenment Britain', BJHS (2013) 46(3), pp. 359-87; Susan Lawrence, 'Educating the senses: students, teachers and medical rhetoric in eighteenth-century London', in W.F. Bynum and Roy Porter (eds.), Medicine and the Five Senses, Cambridge: Cambridge University Press, 1993, pp. 154-78, 170-1.

4 Lorraine Daston, 'On scientific observation', Isis (2008), 99(1), pp. 97-110, 98.

5 On intersensoriality see Mark M. Smith, Sensing the Past: Seeing, Hearing, Smelling, Tasting, and Touching in History, Berkeley: University of California Press, 2007; Alain Corbin, The Foul and the Fragrant: Odor and the French Social Imagination (Leamington Spa, Hamburg and New York: Harvard University Press, 1986).

6 Alexander Wragge-Morley, Aesthetic Science: Representing Nature in the Royal Society of London, 1650-1720, Chicago: The University of Chicago Press, 2020; Daston, op. cit. (4), pp. 97-110; Jessica Riskin, Science in the Age of Sensibility: The Sentimental Empiricists of the French Enlightenment, Chicago: The University of Chicago Press, 2002; Charles T. Wolfe and Ofer Gal, 'Embodied empiricism', in Wolfe and Gal (eds.), The Body as Object and Instrument of Knowledge, Dordrecht: Springer, 2010, pp. 1-5. For a bibliography of 'disciplining out' see Wragge-Morley, op. cit., pp. 185-6 n. 7.

7 Wragge-Morley, op. cit. (6), p. 3.

8 Lissa Roberts, "The death of the sensuous chemist: the "new" chemistry and the transformation of sensuous technology', Studies in History and Philosophy of Science Part A (1995) 26(4), pp. 503-29, 506-7.

9 Daston's short paper is focused on the visual. Daston, op. cit. (4), p. 107, emphasis hers. 
smelling and tasting in the same manner were his explicit aim for his students. His work thereby allows us to study the development of what we might consider the 'tutored body' in anatomical inquiry: how all sensory experience with the cadaver was deemed consistent across properly trained practitioners. This enabled the subjectivities found in cadavers to constitute anatomical knowledge.

Hunter provides a particularly good case study for the creation of tutored bodies because his anatomical inquiry and pedagogy were intimately linked. Roy Porter argued that his lectures to students acted as de facto publications of his findings and work. ${ }^{10}$ Similarly in his introductory lectures to students he emphasized that his course aimed to teach them to investigate the cadaver as he did himself, thus his pedagogical and experimental use of cadavers overlapped. ${ }^{11}$ My focus in this paper is thereby on the practices that Hunter used to investigate anatomy, for which his work on the gravid uterus provides the most comprehensive set of sources. Analysing the practices that Hunter used to investigate the gravid uterus is a task of "putting effort into imagining them in as much detail as possible'. ${ }^{12}$ Meredith Gamer has emphasized the 'complex material history' attendant on Hunter's work on the gravid uterus, comprising not only Hunter's famous publication, the illustrated elephant folio The Anatomy of the Human Gravid Uterus, Exhibited in Figures (1774), but also the series of preparations, plaster casts and 'twodimensional representations' that were made in relation to it. ${ }^{13}$ Gamer's article emphasizes the importance of preservation to Hunter, which enabled him to see the gravid uterus in different ways. ${ }^{14}$ But preparations, casts and illustrations were not the only kinds of preservation that Hunter made. Alongside these artefacts were writings recording a wider range of Hunter's sensory experience with the gravid uterus. In order to productively imagine Hunter's embodied processes of investigating the gravid uterus in as much detail as possible, I combine analysis of the artefacts of Hunter's work with his writings on it, primarily his neglected, posthumously published work An Anatomical Description of the Human Gravid Uterus (1794).

Planned to complement his famous 1774 publication, An Anatomical Description was published by his nephew Matthew Baillie from an incomplete manuscript on the gravid uterus that Hunter left at his death. Baillie completed the manuscript for publication, but that amounted 'only to a few pages' of text, largely towards the end of the book. ${ }^{15}$ The work both was a description of the gravid uterus and gave instructions on replicating Hunter's work to the reader, although since the work was intended primarily for a medical audience, a certain amount of basic knowledge of the operations of, for example, injecting vessels with various substances such as wax was assumed. This example of Hunter's writings expands the range of media through which his work on the gravid uterus can be understood. An Anatomical Description provides substantial evidence of how he worked to create anatomical knowledge with his own body and records a range

10 Roy Porter, 'William Hunter: a surgeon and a gentleman', in Bynum and Porter, William Hunter, op. cit. (3), pp. 7-34, 24-5.

11 Hunter, op. cit. (1), pp. 108-9.

12 Ludmilla Jordanova, The Look of the Past: Visual and Material Evidence in Historical Practice, Cambridge: Cambridge University Press, 2012, p. 53.

13 Meredith Gamer, 'Scalpel to burin: a material history of William Hunter's Anatomy of the Human Gravid Uterus', in Mungo Campbell and Nathan Flis (eds.), William Hunter and the Anatomy of the Modern Museum, New Haven, CT and London: Yale University Press, 2018, pp. 109-25, 110-11.

14 Gamer, op. cit. (13), pp. 117-18.

15 Matthew Baillie in William Hunter, An Anatomical Description of the Human Gravid Uterus, London: J. Johnson and G. Nicol, 1794, p. viii. On Baillie's use of this work see Richard T. Bellis, “'As to the plan of this work ... we think Dr. Baillie has done wrong”: changing the study of disease through epistemic genre in Georgian Britain', Notes and Records: The Royal Society Journal of the History of Science (2021) 75(1), pp. 39-58. 
of his sensory interactions with, and experiences of, the cadaver in a way that an illustration or preparation could not - how operations felt, heard, tasted and smelt was valuable information for the anatomist, but was left uncaptured in images and objects. Hunter's writings thus enable the historian to understand better the experience of the anatomist's body during dissection and how that related to his scientific understanding of anatomy. ${ }^{16}$ Considering Hunter's work with the gravid uterus as a practice that engaged all the senses broadens historical understanding of his epistemology - it may well have been 'fundamentally a visual one', but it was underpinned by a range of sensory engagements with the cadaver. ${ }^{17}$

The role of senses other than vision has been of increasing interest to historians of anatomy, particularly the sense of touch, although much of that analysis has been at the level of the anatomical museum rather than anatomists' practice. Focusing on the role that John Hunter's museum played in the construction of anatomical power relations in Georgian London, Simon Chaplin has argued that anatomists' sense of touch was central to their self-fashioning and authority. ${ }^{18}$ More broadly, touching and handling were an important part of audiences' interactions with anatomical collections and, as Rina Knoeff has demonstrated, were central to the working nature of Frederick Ruysch's collection. ${ }^{19}$ Historians' focus on the museum may be due, in part, to the difficulty of recovering evidence of such interactions elsewhere: Anita Guerrini observes that whilst all the senses certainly were engaged in the anatomy theatre, student notes from Hunter's lectures focused on the visual at the expense of other senses. ${ }^{20}$

The first section of this paper therefore focuses on how Hunter wrote about the senses in An Anatomical Description, paying particular attention to how Hunter worked to guarantee consistent experience across his students by using simple comparative metaphors. I show that, for Hunter, experimenting with the cadaver was fundamentally about observing it in as many ways as possible. Different experimental techniques - ranging from the simple to the complex - engaged the senses in different ways, so anatomical inquiry was

16 As Karen Harvey explains, documents written by individuals are a vital source for understanding embodiment, which she defines thus: 'Embodiment refers to a person's perception or experience of the body and their understanding of how the body relates to other aspects of their consciousness or being'. My interpretation of this in relation to Hunter is to consider his scientific understanding of anatomy as part of his consciousness, and that he experienced his own body during dissection. Karen Harvey, 'Epochs of embodiment: men, women and the material body', Journal for Eighteenth-Century Studies (2019) 42(4), pp. 455-69, 456-7.

17 Jordanova, op. cit. (3), p. 396. Martin Kemp, 'True to their natures: Sir Joshua Reynolds and Dr William Hunter at the Royal Academy of Arts', Notes and Records: The Royal Society Journal of the History of Science (1992) 46(1), pp. 77-88.

18 Simon Chaplin, 'The divine touch, or touching divines: John Hunter, David Hume, and the Bishop of Durham's rectum', in Helen Deutsch and Mary Terrall (eds.), Vital Matters: Eighteenth-Century View of Conception, Life and Death, Toronto: University of Toronto Press, 2012, pp. 222-45.

19 Rina Knoeff, 'Touching anatomy: on the handling of preparations in the anatomical cabinets of Frederick Ruysch (1638-1731)', Studies in the History and Philosophy of Science Part C (2015) 49, pp. 32-44; Anna Maerker, 'Towards a comparative history of touch and spaces of display: the body as epistemic object', Historical Social Research (2015) 40(1), pp. 284-300.

20 Anita Guerrini, 'The value of a dead body', in Deutsch and Terrall, op. cit. (18), pp. 246-64, 251. An alternative mode of analysis is the re-creation of artefacts. Marieke M.A. Hendriksen has made corrosion casts based on eighteenth-century recipes as a way of gaining 'a deeper, more holistic understanding of historical practices', although she cautions that they are not historical experiences in themselves. Marieke M.A. Hendriksen, 'Casting life, casting death: connections between early modern anatomical corrosive preparations and artistic materials and techniques', Notes and Records: The Royal Society Journal of the History of Science (2019) 73(3), pp. 369-97, 380. Re-creation of scientific experiments has a long legacy in the history of science, beginning with Otto Sibum's work on the mechanical value of heat. A good survey is Simon Werrett, 'Matter and facts: material culture and the history of science', in Robert Chapman and Alison Wylie (eds.), Material Evidence: Learning from Archaeological Practice, London: Routledge, 2015, pp. 339-52. 
focused on gaining a range of sensory experiences with the cadaver. Potentially, individuals investigating cadavers might have different experiences, despite adopting similar techniques - but Hunter expected diligent students to experience cadavers in the same way as he did. God, after all, had guaranteed it. Espousing a type of natural-theological argument that Alexander Wragge-Morley has termed 'physico-theology', Hunter argued that apprehending God's creation through anatomy was pleasurable to all those who engaged with His creation appropriately. Employing a strategy also used by the seventeenth-century anatomist Thomas Willis, Hunter made metaphorical comparisons of anatomical objects with everyday objects that could directly engage the senses. These metaphors were intended to fix the ideas of anatomy in the mind, and to enable them to be experienced in the same, pleasurable way enjoyed by the anatomist. The use of metaphor was thus intended to effect psychological changes in his audience in order to ensure that their perceptions were in accord. Hunter developed this strategy further by introducing material objects, such as anatomical preparations, in the lecture theatre to students, engendering consistent sensory experience between them. ${ }^{21}$

Central to Hunter's expectation of consistency between himself and his students was their diligence in studying anatomy. This was not guaranteed. Hunter emphasized the need for students to actively engage with and reflect upon their sensory experiences as part of their learning, an activity that - as the second part of this article investigates was also necessary for Hunter himself. Again, I focus on Hunter's writing techniques: in this case, his use of metaphorical language to indicate uncertain states in the cadaver, which required both experience and reflexive judgement to understand. Here, we see the clearest link between Hunter's work and the activities of contemporary chemistry practitioners. Hunter was something of a sensuous chemist himself in the way that he investigated, for example, the amniotic fluid. This, in combination with other experiences of the cadaver provided his audiences with a multisensory understanding of the gravid uterus. I demonstrate this particularly in relation to the process of injection. As noted earlier, Hunter assumed that his audience would be in possession of this knowledge, so in order to explore this, I turn to one of his contemporaries. Charles Nichols Jenty wrote a detailed account of injection based on Alexander Monro primus's method. Since Hunter also learnt preservation methods from Monro primus, Jenty's description has the twin advantages of broadening the scope of both An Anatomical Description and the applicability of Hunter's work to eighteenth-century anatomy more generally.

In the third section I combine the complex material history of Hunter's work with further analysis of An Anatomical Description, focusing on the investigations that Hunter made into the thickness of the uterus and into the inner muscular fibres of the gravid uterus respectively. This combination enables investigation into the embodied processes through which Hunter investigated the gravid uterus. I show that preservations not only were records of parts but retained sensory information in different ways - in text, image and preparation. Their combination was a powerful tool through which Hunter could demonstrate and generate anatomical knowledge. This aided the recall of different states of the cadaver and investigation into new ones, which combined to increase the range of sensory engagements with the cadaver. Preservations of all kinds retained information that allowed newly obtained cadavers to be investigated in different ways.

21 I use the term 'engendered' here to indicate that Hunter's teaching consisted of more than 'training' or 'sensitizing' his students to the experiential knowledge potentially available in the cadaver - it intended to remake their bodies as well as their minds. 


\section{Writing on the senses in An Anatomical Description}

As his museum collection attests, Hunter took every opportunity he could to examine pregnancy in all its stages. However, An Anatomical Description was largely focused on describing the gravid uterus as it appeared in the ninth month of pregnancy. In the Gravid Uterus Hunter intimated that there was a certain amount of serendipity in focusing on the latter stages of pregnancy - the impression in the introduction is that the women depicted were simply the bodies that he and his assistants were able to acquire. ${ }^{22}$ But in his later writing he emphasized the specific suitability of the bodies of women in the late stages of pregnancy for his work: they were better suited to the kind of sensorial interaction and manipulation that Hunter wanted to perform. As he put it, "[When] the fruit of the womb is then come to its full perfection, [it] bears examination better, and all the minute organization is become more the object of sense and experiment'. ${ }^{23}$ Not only could more be sensed, but also more could be made to be sensed.

Such interaction between the cadaver and the anatomist's senses created experiential knowledge that Hunter attempted to preserve in as many ways as possible, through objects and images, but also through writing. The variety of ways in which Hunter attempted to retain the sensorial information gained in his interactions with the dead body speaks both to the value of such interactions and also to their wide-ranging nature: it was necessary to bring a range of approaches to the task of preserving these experiences because they were themselves so varied. Every cadaver was valuable as it provided further sensory engagements that could be preserved. Indeed, at times, methods of preserving cadavers provided specific experiences with the body that produced valuable information for Hunter. This section focuses on the sensory observations that Hunter preserved through his writings and explores how his writings were intended to engender consistent sensory experiences in his students and readers, particularly through the use of metaphors in his work.

Hunter's experimentation on the gravid uterus began before he commenced teaching. He stated in An Anatomical Description that he first 'injected the vein of the navel string, while the placenta adhered to the uterus', before making a subsequent dissection in 1743. ${ }^{24}$ This was early in Hunter's career, after he had completed his education under the man-midwives William Smellie and James Douglas in London. It was after his return from Paris in 1742, but before he began his course of anatomical lectures in 1746, and four years before he acquired the first body depicted in Gravid Uterus. ${ }^{25}$ The quite specific dating - the only such date that appears in the book - indicates that he undertook dissections of the gravid uterus prior to 1750 , although the dating might be an attempt by Hunter at retaining priority over the discovery of the foetal circulation claimed by his brother John, who joined him in London in $1748 .^{26}$ But 1743 was also the middle of a productive period

22 William Hunter, Anatomia Uteri Humani Gravidi Tabulis Illustrata (The Anatomy of the Human Gravid Uterus Exhibited in Figures), Birmingham: John Baskerville, 1774, preface.

23 Hunter, op. cit. (15), p. 1.

$24 \mathrm{He}$ found that 'in separating these two parts, it was evident that the injection had no where passed farther than the placenta'. Hunter, op. cit. (15), p. 48.

25 Hunter, op. cit. (22), preface. On Hunter's education see T. Gelfand, 'The "Paris manner" of dissection: student anatomical dissection in early eighteenth-century Paris', Bulletin of the History of Medicine (1972) 46(2), pp. 99-130; Fenwick Beekman, 'William Hunter's early medical education: part I his studies under William Cullen and at Edinburgh with Alexander Munro', Journal of the History of Medicine and Allied Sciences (1950) 5(1), pp. 72-84; Beekman, 'William Hunter's early medical education: part II he goes to London to complete his studies and remains there', Journal of the History of Medicine and Allied Sciences (1950) 5(2), pp. 178-96. See also Samuel Foart Simmons and John Hunter, William Hunter 1718-1783: A Memoir (ed. C. Helen Brock), Glasgow: University of Glasgow Press, 1983.

26 The date 1743 contradicts Hunter's statement in Gravid Uterus that 'in the year 1751 [later stated as 1750] the author met with the first favourable opportunity of examining, in the human species, what before he had 
of anatomical investigation for Hunter. He presented his first paper, 'Of the structure and diseases of articulating cartilages', to the Royal Society in June 1743, and appears to have been working to prepare anatomical materials for use in teaching. ${ }^{27}$ Certainly, by that point in his career he had acquired an excellent knowledge of different preparatory techniques and confirmed the importance of dissecting cadavers first-hand for his work. ${ }^{28}$ Given Hunter's subsequent practice as a man-midwife, it seems likely that he took every possible opportunity to examine pregnant women, and, if his own dating is accurate, had at least thirty years of experience in doing so by the time the Gravid Uterus was published. $^{29}$

Experimenting with the gravid uterus was a process of experiencing the cadaver in various ways, with the application of different dissection and preparatory techniques crucial to enabling those experiences. In the eighteenth century, preservation techniques were often experimental either because they were exploratory in themselves (as injecting vessels with various substances could be), or because they allowed instances of the same anatomical structure to be used in different ways with the results preserved. ${ }^{30}$ Alongside the quite complex processes of preservation were simpler techniques. For example, the description of pulling at 'a narrow piece of the uterus ... cut quite out through and through, it is so loose and ductile, that it can be readily drawn out to at least double its natural thickness' emphasized the lax, soft and loose texture of the pregnant uterus. $^{31}$

Different techniques engaged all the senses in various ways. Dissection with a knife made parts, such as the corpus luteum in the ovary, 'sensible both to the sight and touch'. ${ }^{32}$ A 'gentle putrefaction' - no doubt engaging the smell - could be used to make the umbilical portion of the placenta take on 'the appearance of a tree whose branches divide to an almost infinite minuteness'. ${ }^{33}$ Inflating parts such as the placenta enabled the anatomist to hear and feel their own breath enter and leave the corpse. ${ }^{34}$ Hunter

been examining in brutes'. Both dates can be maintained as correct if we assume that the earlier dissections were unfavourable to illustration in the manner Hunter desired. Hunter, op. cit. (22), preface. On the dispute over the foetal circulation see Andrew Cunningham, The Anatomist Anatomis'd: An Experimental Discipline in Enlightenment Europe, London and New York: Routledge, 2016, pp. 291-3.

27 Gelfand, op. cit. (25), p. 99.

28 On how Hunter learnt preparatory techniques see Guerrini, op. cit. (20), pp. 246-64. On his experience with cadavers in Paris see Gelfand, op. cit. (25), pp. 99-130.

29 This contradicts Mungo Campbell's assertion that Hunter's investigations of the human gravid uterus began with the first cadaver depicted in Gravid Uterus. Mungo Campbell, 'The anatomy of the human gravid uterus', in Campbell and Flis, op. cit. (13), pp. 248-51, 248. On Hunter's practice as a man-midwife see Adrian Wilson, 'William Hunter and the varieties of man-midwifery', in Bynum and Porter, William Hunter, op. cit. (3), pp. 343-69; Wilson, The Making of Man-Midwifery: Childbirth in England, 1660-1770, Cambridge, MA, Harvard University Press, 1995, pp. 175-84.

30 On exploring the vessels using injections see Marieke M.A. Hendriksen, 'Anatomical mercury: changing understanding of quicksilver, blood, and the lymphatic system, 1650-1800', Journal of the History of Medicine and Allied Sciences (2014) 70(4), pp. 516-48. On the way preparations enabled experimentation with the same part see Richard T. Bellis, 'Making anatomical knowledge about disease in late Georgian Britain, from dissection table to the printed work and beyond: Matthew Baillie's Morbid Anatomy and its accompanying engravings', PhD thesis, University of Leeds, 2019, pp. 89-92.

31 Hunter, op. cit. (15), p. 25.

32 Hunter, op. cit. (15), p. 14.

33 Hunter, op. cit. (15), pp. 39-40. That Hunter does not explicitly mention smell is likely part of wider attempts to 'deodorize' in the period. Mark Jenner, 'Follow your nose? Smell, smelling, and their histories', American Historical Review (2011) 116(2), pp. 335-51, 340.

34 For example, 'If a blow-pipe be thrust into the substance of the placenta any where, the air which is blown into the cellular part opens and rushes out readily by the open mouths both of arteries and the veins', Hunter, op. cit. (15), p. 46. 
described the taste of amniotic fluid as 'saltish'. ${ }^{35}$ Although many of these sensations were transient, they were nevertheless recorded in An Anatomical Description as important pieces of what Hunter described in his introductory lectures to students as 'data'. There were normative sensations experienced when investigating the gravid uterus according to Hunter's approach. As a result, a consistency in the sensory experience of fellow anatomists was assumed. If they undertook the same work in the same manner, they would find, for instance, that the texture of the internal surface of the amnion was 'smooth and glossy', or that looking through a magnifying glass would show 'transparent ramifying vessels' emerging from the chorion near the edge of the placenta, or that it was impossible to pass a bristle through the 'little pit, which looks like a hole', on the outside of the ovary. ${ }^{37}$ The application of the correct procedures in the correct manner would yield consistent observations across Hunter's students.

For Hunter, this normativity of experience was guaranteed by God. In his introductory lectures (published posthumously in 1784 as Two Introductory Lectures) Hunter advocated a version of the argument by design; he confessed that the senses were 'imperfect' and that we 'cannot pretend to reach every part of a machine [human beings]' God had created. ${ }^{38}$ Nevertheless, the senses offered the best mode of investigation, as when they were appropriately engaged they were able to ensure that one's 'ideas are clear, and make a lasting impression upon his memory'. ${ }^{39}$ For Hunter, such ideas were pleasurable: 'Who can know and consider the thousand evident proofs of the astonishing art of the Creator, in forming and sustaining an animal body such as ours, without feeling the most pleasing enthusiasm? ${ }^{40}$ This holds closely to what Alexander Wragge-Morley has identified in the work of seventeenth-century natural philosophers, including the anatomist Thomas Willis, as 'physico-theology', a form of natural theology that encouraged the aesthetic appreciation of God's design in nature. ${ }^{41}$ This implied not only a personal relationship with God and His creation, but a method of communication too. Natural philosophers worked to discover God's design in nature, experienced pleasure on finding it, and then communicated their findings in order to improve their audience's 'taste', attempting to engender in their audience the same pleasurable experience that the natural philosopher had experienced through their discovery. ${ }^{42}$ Hunter was clear that the attentive student ought to find the same 'pleasure and advantage' in the study of anatomy as he did. ${ }^{43}$ Experiencing such pleasure was vital to ensuring that their sensory experience of dissection was consistent with his.

A crucial strategy that Hunter used to engender such consistency of experience was the use of metaphors and similes, a strategy that stemmed from physico-theology. As Wragge-Morley explains, Willis used simple, comparative metaphors to cultivate his audience's taste (that is, discrimination or perception) as an 'embodied process' using 'medium-scale, commonplace objects' as comparison that made the 'obscure and

35 Tasting does not imply ingesting. Hunter, op. cit. (15), p. 61.

36 He described his work to students thus: 'To lay before you the structure of the parts, and the known phenomena, as data'. Hunter, op. cit. (1), p. 97, emphasis his. This was intended to underpin physiology, which was explored theoretically in this period. See Cunningham, op. cit. (26), pp. 156-65; Andrew Cunningham, 'The pen and the sword: recovering the disciplinary identity of physiology and anatomy before 1800. I: old physiology - the pen', Studies in History and Philosophy of Science Part C (2002) 33(4), pp. 631-65.

37 Hunter, op. cit. (15), pp. 51, 53, 74.

38 Hunter, op. cit. (1), pp. 74, 80.

39 Hunter, op. cit. (1), p. 87.

40 Hunter, op. cit. (1), p. 64.

41 Wragge-Morley, op. cit. (6), pp. 22-3.

42 Wragge-Morley, op. cit. (6), p. 137.

43 Hunter, op. cit. (1), p. 108. 
difficult-to-imagine structures of the brain and nerves easier to apprehend'. ${ }^{44}$ This was intended to be gratifying to the reader, in part because the metaphors addressed the senses, creating a more forceful memory of the object of their reading so that the fabric of the brain and nerves themselves were altered, better to apprehend the pleasures associated with the recognition of God's design of nature in the future. ${ }^{45}$ Such metaphors were thus viewed as being able to effect psychological change in their audience, and Willis used them regularly. Wragge-Morley explains that there are 158 simple comparative metaphors and similes in the section of Willis's (much longer) text on the brain signalled by the (translated) phrase 'as it were'. ${ }^{46}$ Undertaking a similar search of Hunter's An Anatomical Description using the search term 'like', I found nineteen positive, adjectival comparisons to simple objects (as opposed to variations on 'not like' (six) or compound words such as 'sheath-like' (four)). ${ }^{47}$ Typical examples, some of which were repeated, are:

'like a bladder of water not quite full'

'like the sticks of a fan'

'like a tough jelly'

'like a rope'

'like a fine thread'

'like water'

'like the cipher 8 '

'like the coilings of a snake'

'like lace'

'like a thin besmearing plaster'

'like a very small dark circle'. ${ }^{48}$

In other words, these comparisons were made consistently with everyday objects, such as rope, lace or thread, or familiar concepts, such as the number eight or a snake's coil. Their ease of comprehension by the reader, typically in visual or tactile terms, enabled the comprehension of the anatomy of the human gravid uterus in a manner consistent across anatomists.

Alongside these simple comparisons were more complex ones that referenced anatomical findings directly (sixteen). For example, the corpus luteum was described as "like glandular flesh' because of its vascularity, tenderness and friability. ${ }^{49}$ Such comparisons worked in two ways. First, if the reader had anatomical experience, these similes might act in the same way as simple comparisons did: as a way of apprehending the structure through sensory memory - to understand the texture of the corpus luteum recall the crumbly and tender texture of glandular flesh. Second, the linking of two anatomical textures in this way meant that if one could gain experience of one of these textures, then they would gain knowledge of the other.

It is notable that whilst simple comparative metaphors might invoke sight and/or touch, these more complex comparisons were primarily concerned with touch, a harder-to-comprehend sensory experience. Hunter thereby employed Willis's strategy

44 Wragge-Morley, op. cit. (6), pp. 138, 145-50.

45 Wragge-Morley, op. cit. (6), pp. 153-8.

46 Wragge-Morley bases this analysis on Samuel Pordage's translation. Wragge-Morley, op. cit. (6), pp. 147-8. 47 Adjectival as opposed to 'like' as a verb, adverb, discourse marker, discourse particle or quotative. Compound words found were: 'sheath-like', 'dish-like', 'snake-like', and 'cream-like'. Hunter, op. cit. (15), pp. 23, 38, 46, 76 .

48 'As it were' was not used by Hunter; 'as' yielded too large and inclusive a result for my purposes here. Hunter, op. cit. (15), pp. 3, 24, 32-3, 34-5, 37, 54-5, 69, 81, 86-7.

49 Hunter, op. cit. (15), p. 14. 
and extended it. He tried others too. As he was keen to point out in his introductory lectures, he made sure that students were 'not simply hearing a lecture, but feeling a variety of interesting objects', which was 'the best method of fixing them [ideas] for ever in the memory'. ${ }^{50}$ Of course, Hunter's variety of objects referred specifically to preparations, a material method of cultivating taste not available to Willis as methods of preserving the cadaver were in their infancy in Willis's lifetime. But the theological reasoning was the same: experiencing the variety of interesting objects would engender pleasure, consistent across anatomists, which would work to fix that experience in the student's mind.

\section{Actively engaging the senses}

Hunter expected consistent anatomical experiences across practitioners and students who were appropriately attuned to God's creation. To gain such consistency not only required that practitioners develop specific skills (such as knifework), it also required that practitioners' senses were appropriately attuned to the cadavers being dissected. This mirrored contemporary chemistry, which Lissa Roberts has described as students becoming 'sensitized to the point that they could use their bodies to detect all the subtle qualitative distinctions necessary to pursue chemistry with success'. ${ }^{51}$ In a similar vein, Hunter advised his students that practice and deliberation on their experiences of dissection would attune their senses. As he explained in his introductory lectures,

Our lectures are not intended to make men Anatomists, but only to furnish them with such a knowledge of the subject, as will enable them to prosecute the study with success; which can be done only by the labour of their own hands, by an examination with their own senses, and by reflecting and exercising their own faculties upon their own observations. ${ }^{52}$

Thus it was not simply the case that passive sensory experience would lead to anatomical knowledge; the diligent student - and by extension the diligent practitioner - had to actively think through their sensory experience. We saw in the examples of the previous section that simple comparisons between textures were a useful tool by which Hunter expressed how the cadaver felt once he had experienced it sensorially in different ways. In this section, I focus on the processes of dissection through which Hunter experienced and reflected on his senses. Such processes and operations typically engaged more than one sense at a time-most commonly sight and touch-particularly if they were multifaceted as well as multisensory processes, like the injection of the vessels of the gravid uterus. Not only did the injection of substances into the vessels require sensory knowledge of the cadaver, but it also required a good degree of sensory knowledge of the chemical substances, such as wax and mercury, being injected. Before discussing the intricate process of injection, I therefore focus on two simpler examples of anatomical and chemical processes in Hunter's work first: respectively how he separated the umbilical part of the placenta from the uterine, and his chemical work on the amniotic fluid. I then examine the account of injection given by Charles Nicholas Jenty, as Hunter gave few details of his own injection practices in An Anatomical Description. Once Jenty's work has been outlined we return to An Anatomical Description and Hunter's injection of the cellular part of the placenta.

50 Hunter, op. cit. (1), pp. 101, 103, 108.

51 She terms such a process 'sensuous technology'. Roberts, op. cit. (8), p. 507.

52 Hunter, op. cit. (1), p. 108. 
Hunter's method for separating the two parts of a placenta (the uterine and the umbilical) was achieved through putrefaction followed by 'gentle rubbing and washing'. Doing so 'always destroys the uterine portion, which is more tender, and melts down by putrefaction'. ${ }^{53}$ Essentially, the operation described here is leaving the placenta to rot before carefully removing the putrefied part - the uterine portion of the placenta - in order to be left with the umbilical part. But as the complex metaphorical language Hunter used to describe the aspects of the process that required physical interaction with the cadaver attests, the process itself resisted linguistic expression, and thereby reduction to being simply a passive experience: 'gentle' and 'tender' are tactile adjectives that indicate an imprecise level of force and the tissue's subjective state respectively; 'melts' is a verb which here describes an imprecise and incomplete progression. ${ }^{54}$ Though Hunter's description provides readers of An Anatomical Description with instructions about how to achieve an expected result, their imprecision at vital points of the processes described demonstrates the necessity both to experience and to analyse the process in order to properly execute it. Judging whether the uterine portion of the placenta was sufficiently rotten would include visual, tactile and olfactory comparison with its initial state over the course of a few days; the pressure applied with the fingers, hand and arm when gently rubbing might be increased or decreased depending on the response of the tissue; when to wash the surface was similarly dependent on the interplay between sensory experience and one's reflection upon it.

Analysis of the body's fluids required a similar interplay. When investigating the liquids found in the gravid uterus, Hunter combined sensory information with broader reflections. The 'liquor amnii' (amniotic fluid) was first described by sight: 'It is quite fluid ... pretty transparent; although sometimes a little foul or muddy'. But his experience as a man-midwife enabled him to give accounts of the different colourations of the fluid one might encounter: green indicated that the fluid was mixed with the 'child's meconium', while red fluid indicated blood and that the child was very likely dead. ${ }^{55}$ Following these initial observations Hunter then outlined his experiments with the liquid in the manner typical of a sensuous chemist of the period: he heated it, mixed it with common acids (nitrous or muriatic), evaporated it, smelled it and, as we saw above, tasted it. $^{56}$ This created different sensory experiences that served to provide a full picture of the nature of the amniotic fluid. The variety of sensory engagements with this one substance demonstrates the complex and multifaceted nature of such learning - experiential knowledge of the amniotic fluid was based on seeing, touching and tasting it, but could not be reduced to any one of those senses. Instead, knowledge of the body's substances was created at the intersection of those sensorial experiences and his active analysis of them, even when one was prioritized in Hunter's description.

With this in mind, we turn to perhaps the most important method of experimentation and preservation that Hunter employed in his work on the gravid uterus: injection. There were three main advantages of injecting vessels for anatomists: (i) they allowed vessels to be seen more clearly, (ii) they could demonstrate parts of the body, and (iii) they could show how different appearances of the body were related to the vessels. Such uses were crucial to the Hunter brothers in their discovery of the separate circulations of the foetus and the mother as they made those circulatory systems visible. For example,

53 Hunter, op. cit. (15), p. 43.

54 The literary scholar Joe Moshenska has argued that there are 'two rich sets of connections between touch and metaphorical expression', as touch, which resisted full linguistic expression, both served metaphorical expression and required metaphor for expression. Joe Moshenska, Feeling Pleasures: The Sense of Touch in Renaissance England, Oxford: Oxford University Press, 2014, p. 5.

55 Hunter, op. cit. (15), p. 60. There are similarities to uroscopy in this initial analysis.

56 Hunter, op. cit. (15), p. 61. 
(i) Hunter explained that one can inject, and thereby see the vessels of, the whole umbilical system through the vein, with 'the fluid returning from the veins into the arteries ... the injected fluid is confined to the umbilical vascular system'. ${ }^{57}$ In the section on the thickness of the uterus, Hunter explained that (ii) the vascularity of the part was central to its thickness by comparing the part prior to and after injection:

When not injected, its more common thickness is from one to two-thirds of an inch; when its vessels, and particularly its veins, are pretty well filled with wax, its thickness is thereby considerably increased, more especially when the placenta is fixed, on account of the number and size of the vessels at that part. ${ }^{58}$

And (iii), the process of injection might make it apparent why parts would appear different to anatomists depending on circumstance, such as for the veins that transported blood from the placenta to the uterus:

In injecting them, we observe that at first they become turgid, and project on the outer surface of the uterus; but in proportion as we throw a greater quantity of wax into these vessels, they grow more flat and obscure; because the uterus itself becomes more filled and tense, which has the effect of compressing the veins that run in its substance. ${ }^{59}$

The importance of injection to seeing parts of the gravid uterus was thus well attested in An Anatomical Description. However, the process was complex and often difficult, and relied on other senses for its successful operation, especially that of touch, and required the anatomist to become sensorially engaged with various fluids and instruments to gain what Marieke M.A. Hendriksen has described as 'somatic tacit knowledge' ${ }^{60}$ As well as knowledge of the cadaver in various states, injection required concrete and tacit knowledge of different substances. Typically, the substance injected into the vessels was wax, though mercury and other fluids (such as water) designed for temporary injections might also be used. ${ }^{61}$ of course, wax is normally solid at room temperature, so it was necessary to warm it in order to inject it into the body. Indeed, this was one of the main attractions of wax, as once it solidified in the body, it would preserve the course of the vessel it had been injected into. But if it was too warm it might damage parts. Hunter appears not to have used thermometers in his work, so instead it was necessary for the anatomist to attune their body to the look, feel and smell of the right temperature for the wax, and how it would interact with the cadaver, which could be very difficult. ${ }^{62}$

Hunter wrote little on the precise methods of injection in An Anatomical Description but a contemporary of Hunter's did, and it is worth briefly turning to this work in order to detail what anatomists needed to attune their bodies towards. Charles Nicholas Jenty published possibly the earliest account of the injection process in English as a prefix to his 1757 work A Course of Anatomico-physiological Lectures on the Human Structure and Animal

57 Hunter, op. cit. (15), pp. 40-1.

58 Hunter, op. cit. (15), p. 15.

59 Hunter, op. cit. (15), p. 18.

60 Hendriksen explains that the term is 'borrowed from Polanski and Collins' and usefully applies it to the making of preparations and injections. Marieke M.A. Hendriksen, Elegant Anatomy: The Eighteenth-Century Leiden Anatomical Catalogue, Leiden and Boston: Brill, 2015, pp. 55-6.

61 A general history of injection in the eighteenth century is Cunningham, op. cit. (26), pp. 231-51.

62 Hendriksen, op. cit. (60), pp. 80-1. The Science Museum website does list a clinical thermometer belonging to John Hunter, so it is possible that the Hunters used thermometers when using wax, but I have not found evidence of that. 
Oeconomy. Jenty is a largely obscure figure in London's mid-eighteenth-century medical world, but he worked as a surgical teacher and man-midwife, and even published an illustrated work on the gravid uterus with Jan van Rymsdyk, the artist who also illustrated Hunter's and William Smellie's works. ${ }^{63}$ Alongside these links, Jenty presented his essay on injection as 'According to Professor Monro's Method'. That is Monro primus, from whom Hunter also learnt some preparation methods. We can thus view Jenty's essay as representative, though not comprehensive, of Hunter's own methods. ${ }^{64}$

Jenty described 'the principal Things' in preparing a subject for injection as dissolving the body's fluids, emptying its vessels, relaxing the solids, and preventing the injection 'from cooling too soon'. ${ }^{65}$ The first step in doing so was to macerate the body or part to be injected in water 'so warm, that you can hold your Hand in it' - what we might describe today as lukewarm water. This would relax the vessels (solids), dissolve the blood (fluids), 'and keep the Injection from hardening too soon'. Too-hot water caused the vessels to shrivel and blood to coagulate in them. This process had to account also for the particular features of the body, such as its age and bulk, ensure that the body was 'perfectly warm throughout', and that as much blood had been evacuated as possible, squeezed out 'at the Apertures by which the Injection is to be made'. Once these preliminaries were complete, it was necessary to attach a pipe to the vessel through which the injection could be made. Beyond the temperature of water, this necessitated the performance of sundry operations using various equipment-namely choosing 'a Pipe a little smaller than the Diameter of the Vessel, and introduce it at an Incision made in its Side, and then, with a waxed Thread, secure it from slipping out'. ${ }^{66}$

Once the pipe was attached, the part was ready to inject. For Jenty, two types of injection were required: a fine injection made from oil of turpentine and dye, and a coarse injection made from a mixture of tallow, 'white Wax', olive oil and dye. ${ }^{67}$ These had to be prepared beforehand and heated to the correct temperature before injection. For the fine injection that was 'no warmer than what you can bear your Finger in', for the coarse injection 'near boiling'. To avoid heat being lost during injection, it was advised to draw boiling water into the syringe directly before use, and heat the pipe attached to the vessel by applying to it a sponge that had been dipped in boiling water. However, this required that 'A coarse Cloth must be wrapped round the Syringe; otherwise you will not be able to hold it'. The next stage was to fill the syringe with the fine injection, after which both the hands and chest would be required: 'introduce the Pipe of the Syringe into that of the Vessel, and press them together, holding this last Pipe firm with the left Hand, and grip[p]ing the Syringe with the other; then pressing your Breast against the Sucker, gently force it down'. Once resistance was felt, the syringe should be drawn back enough to 'empty the nearest large Vessels' before removing the syringe from the pipe, removing any remaining fine injection from the syringe, and filling it with the coarse injection 'immediately'. Then the coarse injection 'must be thrown into the Vessels quickly and

63 Carin Berkowitz, 'The illustrious anatomist: authorship, patronage, and illustrative style in anatomy folios, 1700-1840', Bulletin of the History of Medicine (2015) 89(2), pp. 171-208, 185-6; Cosimo Calabrò, 'Cosmopolitan anatomy and surgery in the age of the Enlightenment: two poles in the career of Charles Nicholas Jenty', MA thesis, McGill University, 2012.

64 Hunter learnt preparation methods from several sources, but the most important were Monro primus, James Douglas and Frank Nichols. See Bellis, op. cit. (30), pp. 87-9.

65 Charles Nicholas Jenty, 'The Art of Preparing and Preserving the Parts of Human Bodies; with that of Injecting their Vessels: According to Professor Monro's Method', in Jenty, A Course of Anatomico-physiological Lectures on the Human Structure and Animal Oeconomy, London: James Rivington and James Fletcher, 1757, pp. clxix-clxx.

66 Jenty, op. cit. (65), p. clxx.

67 Jenty, op. cit. (65), p. clxix. 
forcibly; having always Regard to the Strength of the Vessels'. This was to be continued until resistance was felt, at which point the anatomist should stop in order not to burst the vessels. The process was complete, but the syringe was not to be removed from the pipe until the injection was cold and 'there is no Danger of its running out'. ${ }^{68}$

What is particularly noticeable throughout Jenty's account is the range and subtlety of judgements that were required of the anatomist to successfully inject a part. Fluids of various kinds had to be held at temperatures ranging from lukewarm to 'near' boiling; the pipe had to be fastened to the vessel in a sufficiently secure way; the pressure put through the syringe required a balance of ensuring that the injection flowed firmly through the vessels without breaking them. As outlined above in relation to separating the parts of the placenta, this required knowledge of the parts in different states - here sufficiently macerated and bloodless, then properly injected - and, as discussed in relation to Hunter's chemical work on the amniotic fluid, multisensory knowledge of different substances - how wax looked and smelt as it was heated to near boiling helped judgements regarding its temperature as touching the substance directly became impossible due to its heat, for example (think of how we can judge when water is simmering as a comparison). Moreover, this was knowledge that was required to be employed as part of a multifaceted set of tasks and procedures that required operation within a space, with tools and with the anatomist's body - items had to be at hand, a fire had to be burning to heat the substances, both hands and the anatomist's chest were necessary for the operation of injecting. As well as organization, the successful operation of injection required trial and error, and the triangulation of knowledge and experiences through reflection. Whether the feeling of the pressure of the syringe through the anatomist's chest did indicate that the part was sufficiently injected was only knowable once the injections had dried and could be visually examined. Once seen and considered, the experience of that injection would inform the next injection and how the balance between the injection substance and the fragility of the vessels was experienced through the anatomist's chest.

For example, and returning to An Anatomical Description, Hunter found it possible to fill the cellular part of the placenta from the coat of the navel string when the placenta and its membranes still adhered to the uterus. To do so, he would 'make a slit into the coat of the navel string; there introduce a blunt probe, and force it into the cells of the adjacent part of the placenta; then withdrawing the probe, insinuate an injecting-pipe, and tie it firmly with a broad thread round the navel string. ${ }^{69}$ Force was necessary to ensure the correct insertion of the pipe, and that its ties did not shift during injection. But care was necessary too; too much force would cause misleading results. Hunter had found it was possible to inject from the vein of the navel string to a vessel beyond the placenta (which he assumed was an artery), but only because "upon examination, it was evident that there was extravasation in that part of the placenta'. ${ }^{70}$ In other words, the vessels had broken, likely due to the force of the injection, and the result was an inaccurate observation. This observation was made only after the initial operation and reflection upon it. Thus, to gain useful experiential knowledge, the anatomist had to go through a process of training their own body to have suitable somatic tacit knowledge of substances, apparatus and the cadaver in order that they could successfully complete operations such as injection so that it could provide them with further experience of the cadaver. The writings of Hunter and Jenty may have spelt out the processes and practices involved, but the only way to really learn was by attempting the practices with one's own body.

68 Jenty, op. cit. (65), pp. clxx-clxxi.

69 Hunter, op. cit. (15), p. 47.

70 Hunter, op. cit. (15), p. 49. 


\section{Embodied knowledge and collecting anatomy}

Text was one mode of preservation. In this section, I combine further analysis of An Anatomical Description with consideration of the wider material culture attached to Hunter's investigation of the gravid uterus. Multiple methods of preservation were combined at the school to help retain as much information from individual cadavers as possible. At the same time those preservations had to be potentially representative of whole classes of anatomical parts or bodies. ${ }^{71}$ Examining the full range of Hunter's preservations brings his embodied practice into focus and indicates how such practices made the cadaver an object of investigation. Bodies were made to be objects through preservation methods and then used as objects for further investigations. Here, I focus on two of Hunter's investigative processes related to the gravid uterus: his investigations into determining the thickness of the uterus in different states, and his examination of the inner muscular fibres of the gravid uterus. Both of these investigations resulted in multiple kinds of preserved material as well as representation in the Gravid Uterus. Relatedly, examining these plates and their related material usefully moves away from the historiographical focus on Plate VI, the 'finest in the book'. ${ }^{72}$ These examples demonstrate how preservations of his sensory engagements worked to strengthen his assertions about anatomy, and thereby anatomical knowledge generally.

Collecting multiple preservations at scale was central to Hunter's practice. Doing so gave a material grounding to his work that made his statements on the gravid uterus authoritative and trustworthy. For example, in the section titled 'Of the thickness of the uterus' in An Anatomical Description, Hunter was able to explain that when the uterus appeared thick, it was because the woman under examination had died, and that thickness was not the natural state of the uterus during pregnancy:

Those who say that the uterus grows thicker in the same proportion that its bulk is increased, have probably been deceived by examining the uterus of a woman who died some hours or days after delivery. In that contracted state the uterus is often found even two inches thick; but in all those which I have examined, in the natural distended state, though there was some difference, the thickness of the uterus was but a little more considerable than before impregnation. ${ }^{73}$

Implicit in this statement is acknowledgement of the quantity of bodies that Hunter dissected: not only at least one body each before and after pregnancy, but also at least one body of a woman who died sometime after delivery - and likely more than one of each type. Through describing this experience of bodies at different stages of pregnancy, he was able to emphasize that specific types of body were crucial to accurate observation of the natural state of the gravid uterus. ${ }^{74}$ Furthermore, this experience was supported, and known to be supported, with extant anatomical material. ${ }^{75}$ Hunter's museum catalogue lists, for example, a preparation, RR 8, that showed a 'Transverse Section of the

71 Lorraine Daston and Peter Galison, Objectivity, New York: Zone Books, 2007, pp. 75-6.

72 Karen Harvey, 'Visualizing reproduction: a cultural history of early modern and modern medical illustrations', Journal of Medical Humanities (2009) 31(1), pp. 37-51, 41-2. Quote from Robert Ollerenshaw, 'Dr Hunter's “Gravid Uterus": a bicentenary note', Medical and Biological Illustration (1974) 24, pp. 43-57, 57.

73 Hunter, op. cit. (15), p. 15.

74 Gamer notes that thirteen 'pregnant corpses', three abortions, four miscarriages and one cadaver of a woman who died two days after delivery made up the anatomical base of Gravid Uterus. Gamer, op. cit. (13), p. 114 and n. 26.

75 A survey of the anatomical preparations still in Hunter's collection that correspond to images in Gravid Uterus can be found in N.A. McCulloch, D. Russell and S.W. McDonald, 'William Hunter's Gravid Uterus: the specimens and plates', Clinical Anatomy (2002) 15(4), pp. 253-62. 
Uterus Some Days After Delivery' that had 'contracted to a fifth of its former size; the sides are now about two inches thick, and the cavity about an inch broad, and seven-eighths from before to behind'. ${ }^{76}$ As Alice J. Marshall, who compiled the modern catalogue of the Hunterian collection, observed, this preparation's thickness and bulk can be compared with both the plaster casts in Hunter's collection, which demonstrate the gravid uterus in an uncontracted state, and a number of preparations. ${ }^{77}$ One such preparation, RR 189, was depicted in Gravid Uterus (Figure 1). Plate XXXII, Figure II, shows a longitudinal section of the uterus at three months that gives a sense of the growing, but not thickening, uterus: parts of the lining of the uterus such as the fundus (FFFF) remained a similar size whilst the cavity expanded due to the development of the foetus. ${ }^{78}$

Together these preservations retained the information about the thickness of the uterus in different ways, built useful redundancy into the collection (in the sense that more than one preparation demonstrated the same point), and evidenced how Hunter was able to gain an intersensory sense of proportion about the gravid uterus relating to its length, breadth and depth in various states. It was possible for Hunter to both see and touch several gravid uteruses, attuning his body to its various states. Preserving those states in different ways ensured that Hunter was able more easily to recall those states and his experience of them at a later date, which enabled comparisons between states and therefore the creation of further anatomical knowledge regarding the thickness of the uterus. In the first section we saw that Hunter's use of simple and complex metaphors worked to enable consistent apprehension of anatomy in the mind of the student. This example shows that other methods of preservation could work in the same way for Hunter, as well as for his students.

Mungo Campbell has argued that the plaster casts Hunter made in collaboration with the principal artist of Gravid Uterus, Jan van Rymsdyk, provided a "multiplicity of "gazes"' to students - their three-dimensionality allowed students to circle the cast cadaver, viewing the inner workings of the body from all sides. ${ }^{79}$ These casts have recently been the subject of detailed scientific analysis at the University of Glasgow, which has confirmed that they were made 'using complex piece-moulds, necessary to reproduce the deep relief of the dissection and the specific qualities of the various surfaces imitated'. ${ }^{80}$ As well as enabling seeing, the casts intimated touching the cadaver in two ways. First, because they were designed to be laid flat on a table in the manner of a dissecting slab, the casts gave an impression of the size and heaviness of the cadaver, and indicated that it was something to be handled. Second, the casts emphasized the corpse's potential malleability. Hunter's use of casting demonstrated his ability to affect the inner workings of the body, which echoed Galen's criticism of sculptors who, he argued, could only affect change in surfaces. By contrast, through affecting the inner workings of the body, medical practitioners could, as Joe Moshenska has put it, be involved with 'touching thoroughly and entirely'. ${ }^{81}$ Casts demonstrated this to students in a way that engaged their vision

76 Anon. with notes by William Hunter, Catalogue of Anatomical Preparations, 1770-83, University of Glasgow Library, Archives and Special Collections, MR 19.

77 Alice J. Marshall (ed.), Catalogue of the Anatomical Preparations of Dr. William Hunter in the Museum of the Anatomy Department, 4th edn, Glasgow: University of Glasgow, 1970, p. 668.

78 Hunter, op. cit. (22), Plate XXXII, Figure II; anon. with notes by Hunter, op. cit. (76).

79 Campbell, op. cit. (29), p. 249.

80 Campbell, op. cit. (29), p. 250. See also 'The gravid uterus' (catalogue section) in Campbell and Flis, op. cit. (13), pp. 252-73, 252-9; N.A. McCulloch, D. Russel and S.W. McDonald, 'William Hunter's casts of the gravid uterus at the University of Glasgow', Clinical Anatomy (2001) 14(3), pp. 210-17, 210-12.

81 'Pedagogy and professional practice' (catalogue section), in Campbell and Flis, op. cit. (13), pp. 196-209, 208-9; Moshenska, op. cit. (54), pp. 150-1. On the wider debate over the artistic merits of painted écorché in 


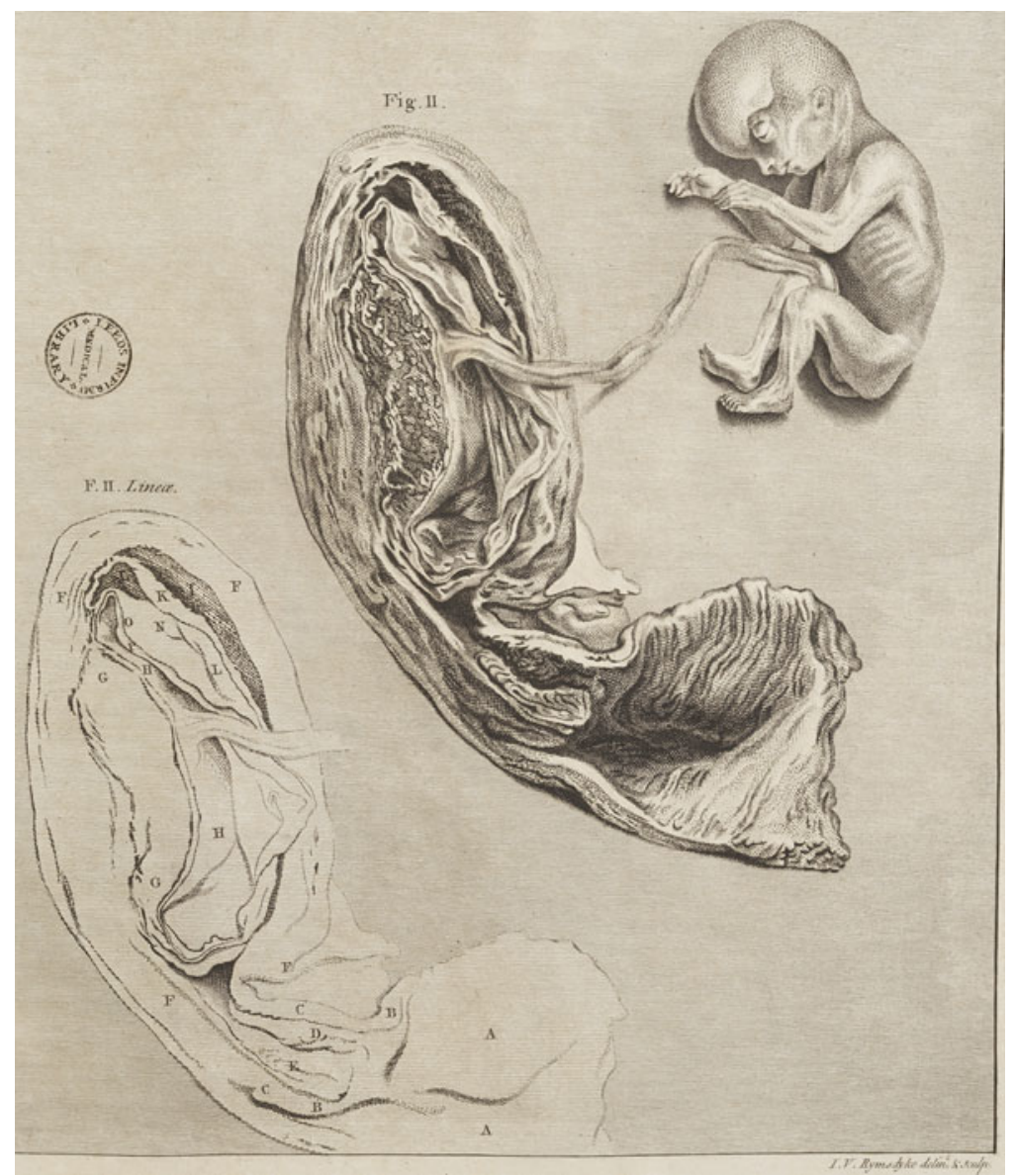

Figure I. William Hunter, The Anatomy of the Human Gravid Uterus Exhibited in Figures, Birmingham: John Baskerville, I774, Plate XXXII, Figure II. Caption reads, 'A longitudinal section of the womb, placenta and membranes; with the child near it, but still attached by the navel-string.' Image courtesy of the University of Leeds Special Collections.

and sense of touch, beginning the process of gaining an intersensory sense of proportion about the cadaver as well as a sense that they could affect the inner workings of the body.

The sensory practices through which anatomists gained knowledge of the cadaver did not always lead straightforwardly to anatomical knowledge, and Hunter admitted difficulties in his perception of the gravid uterus at several points of An Anatomical Description and Gravid Uterus. For example, in his description of the muscular fibres of the uterus, Hunter emphasized the complications that he encountered in understanding that part of the body: 'I have taken considerable pains to trace the arrangement of the uterine fasciculi, but, except upon its inner surface, I have observed nothing but irregularity and confusion'. ${ }^{8}$ Hunter reasoned that this was due to the 'infinite number of the branches and communications of the large veins' as he dissected into the muscular surface of the uterus. ${ }^{83}$

this period see Martin Postle, 'Flayed for art: the écorché figure in the English art academy', British Art Journal (2004) 5(1), pp. 55-63, 55; Kemp, op. cit. (17), pp. 81-2.

82 Hunter, op. cit. (15), p. 26.

83 Hunter, op. cit. (15), p. 28. 
Despite such difficulty, Hunter repeatedly attempted to understand the inner muscular fibres, which did show signs of regularity. He did so in the now familiar manner: by experimenting with different preparatory techniques on cadavers on several occasions, and retaining his experiences as texts, images and preparations. The museum catalogue shows that some preparations were made to demonstrate the inner muscular surface primarily with knifework, such as RR 11, which showed 'the muscular fibres in packets forming vortices or concentric circles', whilst RR 12 showed that the 'muscular fibres appear parallel'. ${ }^{84}$ Preparation RR 15, 'Concentric Muscular Fibres around the Inner Orifice of the Fallopian Tube', showed the same part with the veins injected yellow. Other preparations were made through quite different preparatory techniques. Two preparations described in An Anatomical Description - RR 14, from a woman who died seven days after delivery, and RR 16, from a woman who died in the ninth month, before labour - were 'gave up ... to this pursuit' of understanding the arrangement of the inner muscular fibres in the uterus, as their bodies were particularly suited to the purpose. ${ }^{85}$ Indeed, Hunter described the latter body as 'the most favourable occasion that could be desired'. ${ }^{86}$ That is, these cadavers were used primarily to investigate the muscular fibres of the uterus alone, eschewing other potential uses for investigating the gravid uterus, in the latter case because the corpse was a particularly valuable opportunity to use for this particular experiment. This was a luxury Hunter could afford because he had fostered the bodysnatching trade and could be confident of obtaining further cadavers again in the future. ${ }^{87}$

His mode of investigation on this occasion was to soak the whole uterus in warm water, stretching it gradually before inverting it in order 'to have a full view of its inner surface'. To have a clear view of the inner membrane Hunter removed the decidua, which was 'melted down, and passed off with the lochia', by 'rubbing off this tender membrane with a cloth' in a similar manner to the way he separated the two parts of a placenta described in the previous section. ${ }^{8}$ From these operations, Hunter concluded that there were two centres of muscle fibres in the fundus of the uterus, but that, "When this internal stratum was removed, the fasciculated appearance and regular direction of the fibres was less and less apparent, in proportion as I dissected outwards'. ${ }^{89}$ Despite Hunter's inability to properly perceive the outer muscular surface, he was confident that he understood the arrangement of the inner muscular surface, and depicted RR 16 in Gravid Uterus. Yet even in the illustration, irregularity was depicted, in line with Hunter's aim to produce naturalistic illustrations. ${ }^{90}$ The caption for Plate XIV, Figure II, describes that point $C$ showed 'An irregular stratum of fibres, upon the inside of the circular fasciculi’ (see Figure 2). ${ }^{91}$

84 Anon. with notes by William Hunter, op. cit. (76).

85 Hunter, op. cit. (15), p. 27.

86 Hunter, op. cit. (15), p. 28.

87 However, this would not preclude the sectioning of the cadaver's limbs for student use in learning surgical operations, for example. It is very likely that the sectioning apparent in Plate VI-which has been a source of speculation for historians - was performed for such purposes. On students' use of severed limbs for practising surgical operations see Tania Kausmally, 'William Hewson and the Craven Street Anatomy School', in Piers Mitchell (ed.), Anatomical Dissection in Enlightenment England and Beyond: Autopsy, Pathology and Display, Farnham: Ashgate, 2012, pp. 69-76.

88 Hunter, op. cit. (15), pp. 27-8.

89 Hunter, op. cit. (15), pp. 27-9.

90 Daston and Galison, op. cit. (71), pp. 75-7.

91 Hunter, op. cit. (22), Plate XIV, Figure II, description. 


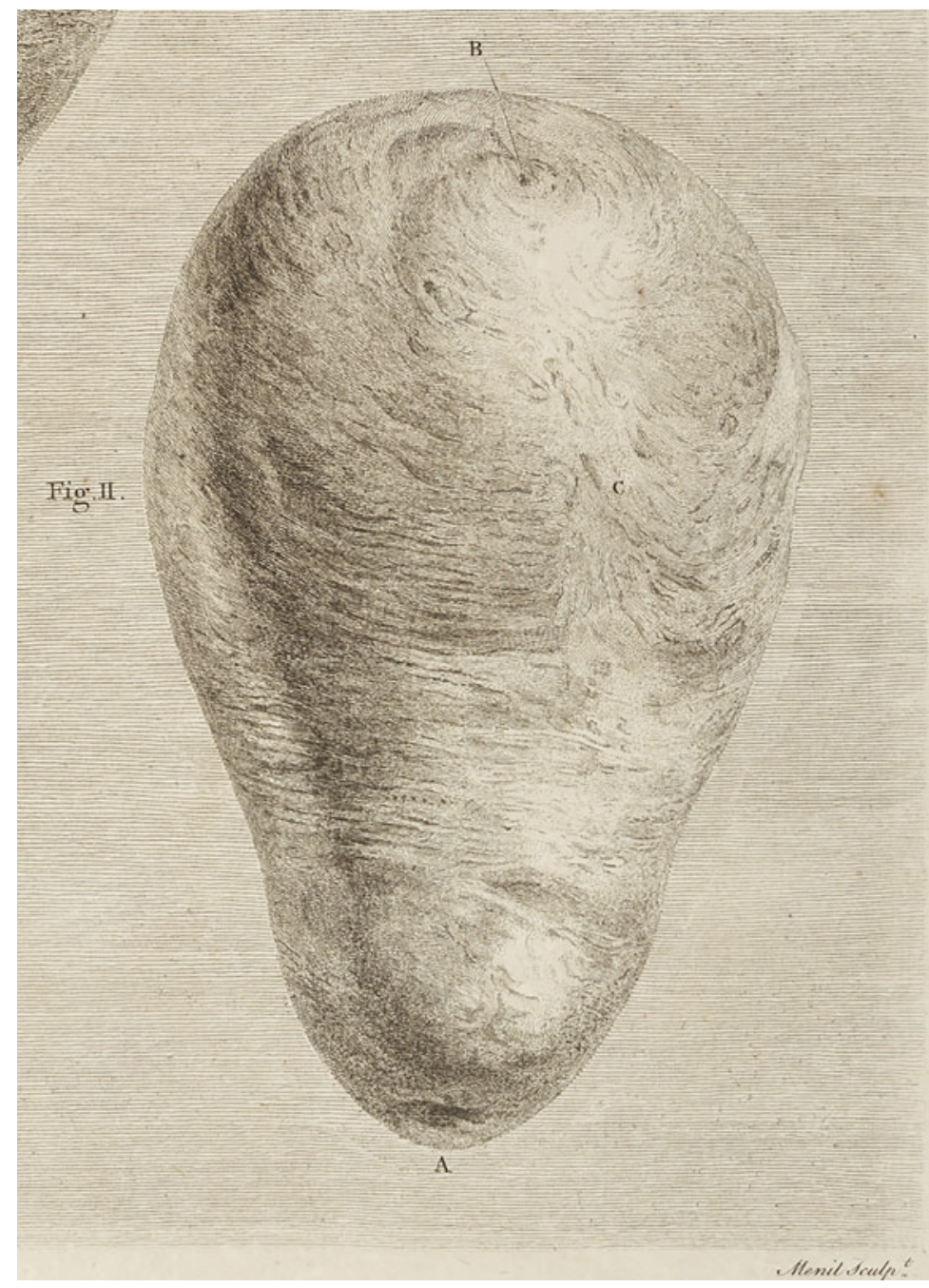

Figure 2. Hunter, op. cit., Plate XIV, Figure II. Caption reads, 'From a fourth subject, at nine months. This shews the disposition of the muscular fasciculi on the inside of the womb, in three different views.' Image courtesy of the University of Leeds Special Collections.

\section{Conclusion}

The admission and retention of anatomical uncertainty within Hunter's writings and collection emphasize its central purpose as an experimental teaching collection. The objects contained within could aid further anatomical work by being resources for active engagement with cadavers, either through being objects of reflection or by preserving observations that could become the basis for further work by Hunter and his assistants. At the same time, these preservations were used to teach students, and this was of fundamental importance in ensuring that students had experiences of the cadaver that were consistent with Hunter's: that is, pleasurable and experienced sensorially in the same way. Through this consistency of experience between practitioners, a practice of anatomy was engendered that was fundamentally grounded in the discernment of subjective states. Hunter 
made the gravid uterus an object of sense and experiment through his ontology of observation.

How, then, did Hunter observe the gravid uterus? He saw, touched, cut, pulled, probed, injected, inflated and smelled the corpse, and tasted its products; he observed it when fresh, soaked it in water and let it rot; he immersed it in spirits and let parts dry out; he applied anatomical methods and he applied chemical methods; but primarily he observed it in as many ways as possible by sensorially engaging with it. Such engagement was complex, the experiential knowledge produced often fleeting. But Hunter worked to preserve as much of this information as possible through the creation of texts, images and objects using anatomical and artistic techniques. Such work was necessarily imperfect - how to truly capture the experience of touching a rotting placenta in words, after all? - but nonetheless crucial to his investigation. With the products of one dissection, it was possible to compare, contrast, experiment, but most of all to gain new experiences of the cadaver, to engage with it afresh once again.

Acknowledgements. My thanks to Susan Bruce who first prompted me to write this paper. Ideas present in this paper stemmed from my PhD research, which was funded by the School of Philosophy, Religion and History of Science at the University of Leeds. Thanks to my supervisory team of Adrian Wilson, Jonathan Topham and Richard Checketts. Further support for this research came from the Leeds Arts and Humanities Research Institute, where I enjoyed a short-term fellowship in 2021. Finally, I am especially grateful for the helpful comments, advice and proofreading help I received from Coreen McGuire, Ludmilla Jordanova, the two anonymous referees and the BJHS editorial team.

Cite this article: Bellis RT (2022). 'The object of sense and experiment': the ontology of sensation in William Hunter's investigation of the human gravid uterus. The British Journal for the History of Science 55, 227-246. https://doi.org/10.1017/S0007087422000024 